\title{
Creating Online Content With Real World Application By Designing And Implementing Online Practicums For Virtual And Physical Environments
}

Bob Barrett, American Public University, USA

\begin{abstract}
Universities need to assess student learning in order to determine if they are reaching the needs of the students, linking learning to course objectives, and determining if their courses have academic rigor. While many courses focus on the immediate course learning objectives, the use of final program projects and program assessments are becoming a key focus point for administrators, accreditors, instructors, and the business community. What do these final assessments tell them or not tell them? What are they searching for in order to satisfy their research and daily needs and questions? In particular, what key program assessments can be useful for these academics, as well as for the students who select to do certain elected assessments?

The purpose of this paper is to focus on the use of online practicum, which serves an alternative to a master's thesis or graduate comprehensive examination. While some students may elect to focus on their research skills or opt for the comprehensive examination, other online students tend to seek other means to have their skills assess and try another area of application. The third option for these graduate students is an online practicum, which is in a form of blended learning. The student chooses a particular industry to explore and work in, as well as creating a learning experience between him or her and a potential employer to apply their current content knowledge to a real world experience. This experience is in the form of a prescribed learning experience that is based on online learning, combined with the student's current skills and content knowledge, and then applied to a real world environment for implementation of their newly created learning contract. This paper will examine the process from the creation of the learning contract to the implementation of the learning experience in this blended learning project. The key emphasis of this paper will be how the online instructor helps to facilitate the learning from a virtual platform, while the student moves into the next level of actual application of his or her skills in a physical working environment and will interact with the virtual instructor through a variety of learning medias as he or she works between these two types of environment towards achieving a set number of hours on the final learning experience, as well as preparing an academic-based, research paper to overview and evaluate the sum of the total learning gained from the practicum.
\end{abstract}

Keywords: Online Learning; Assessment; Virtual Assessment; Online Practicum; Virtual Learning

\section{INTRODUCTION}

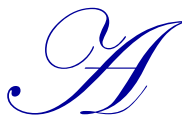

t the end of 2006, 38 U.S. states have established state-led online learning programs, policies regulating online learning, or both. Out of these states, 25 states have state-led online learning programs, and 18 states are home to a total of 147 virtual charter schools serving over 65,000 students (http://www.nacol.org). In 2001, 56\% of traditional learning institutions offered distance learning programs. An additional 12\% of schools stated they planned on adding distance learning programs to their curriculum within the next three years (National Center for Education Statistics, 2003). 
While we have seen technology change continuously in many industries and organizations, so does the skills and abilities of the current and future workforces. Harris (2000) noted that the "new workplace requires a new type of employee, one who is highly skilled, flexible, creative, and attuned to working as a member of a team" (p. 1). In order to prepare our students, we need to focus on different types of learning activities to help best prepare them for the current and future workplaces. Education and training in the workplace has changed drastically, and academia will have to make concessions and implement changes. However, not all educational institutions, or workplaces, are quick to embrace change (or technological changes). This, in itself, can be the problem that many people working with such organizations, or potentially to receive some contact with them, will need to face.

Thus, we can see more universities and colleges striving to achieve better academic standards, as well as achievement results, they are considering different approaches to both their teaching and learning approaches. The Centre for the Study of Higher Education (2011) noted that "many academics are seeking to diversify assessment tasks, broaden the range of skills assessed and provide students with more timely and informative feedback on their progress. Others are wishing to meet student expectations for more flexible delivery and to generate efficiencies in assessment that can ease academic staff workloads" (para. 3). The key purpose of this paper will be to focus on what one university is doing to help "rejuvenate" the learning process, as well as helping to achieve better teaching and learning experiences for everyone involved in the educational experience. As such, we need to examine how assessment plays a key role and function in understanding whether our students are learning key theories, concepts, and principles. Further, we need to discover if they are able to apply this knowledge, or rather content knowledge, to everyday events in their personal and professional lives. As we progress in this paper, we will look at assessments in general and in the online learning environment. Also, we will examine how the use of practicums can be a useful assessment tool for instructors to assess and evaluate their students' learning.

\section{THE ROLE AND FUNCTION OF ONLINE LEARNING AND ASSESSMENTS}

Virtual University Design \& Technology (2010) notes that a good assessment should:

- $\quad$ Measures meaningful learning outcomes

- $\quad$ Does so in a far, reliable, accurate way

- $\quad$ Is easy to administer, score, and interpret

- Informs the teacher about student performance and how they are interpreting course experiences

- $\quad$ Results in a meaningful feedback to the learner

- $\quad$ is itself a learning experience (VD\&T, 2010)

The question is whether we are offering quality assessments in regular brick-and-mortar classrooms or are we offering better assessments in our online (virtual learning environments). If we look at the role and function of assessment, we also have to examine whether the assessment is doable and achievable by our students given their skills, location, and time allotments. Many people can remember taking various assessments during different levels of their education. However, the key question that will be tantamount in our paper's discussion is whether or not people can actually benefit from some assessments and learning that will be sustainable for their current and future career endeavors.

The Centre for the Study of Higher Education (2011) stated that "Successful on-line assessment is most likely if that assessment is aligned with teaching and learning objectives. In other words, there should be a strong relationship between the purpose of on-line assessment task(s) and the intended outcomes of the subject" (p. 6). As noted above, the key purpose of learning is to achieve a given set of objectives and be measureable by some form of assessment. Further, the end result is whether the student can walk away from the course with something that is measureable and particularly useful and memorable for future use. Why is this so critical? While there has been considerable debate as to the value of online learning versus face-to-face learning, one key difference that we have seen is the emphasis of technology in the online learning environment. Thus, many online schools have been focused on offer more interactive and engaging learning activities.

Sewell, Frith, \& Colvin (2010) stated that "an effective online instructor orchestrates a number of interactive learning and assessment activities to guide and document the learning process" (p. 297). Why is this a 
mission for instructors, in particular online instructors, has become a key question for curriculum developers, administrators, and accrediting officials. In the online learning environment, instructors need to meet a certain level of academic standards, as well as engaging the student as if they were in a live face-to-face classroom. As such, there is a set of academic standards for both types of learning environment to achieve and maintain a certain level of academic learning and provide a stimulating learning environment. One way in which these instructors can determine if their students are learning according to the learning objectives is the use of various types of learning assessments. Angelo and Cross (1993) explained that classroom assessment is "an approach to help teachers find out what students are learning in the classroom and how well they are learning from it" (p. 4). One way to find out more about the learning and the levels of learning is to examine type of assessments.

Huba and Freed (1999) developed eight characteristics of exemplar assessments.

- $\quad$ Authentic - reflects real life experiences

- $\quad$ Challenging - stimulates the learner to apply knowledge

- $\quad$ Coherent - serves as a guide for the student to achieve the learning goal

- $\quad$ Engaging - attracts the learner's interest

- $\quad$ Respectful - sensitive to the individual learner's beliefs and values

- $\quad$ Responsive - includes a feedback mechanism to assist the student in the learning process

- $\quad$ Rigorous - requires applied understanding of learning to achieve a successful outcome

- Valid - provides information that is useful to meet the intended learning comes (p.300).

While not all of these characteristics may be found in all types of learning, a healthy mixture of these characteristics can help to provide more substance and variety in the learning process. As more educational institutions strive towards achieving more variety in their assessment instruments, they are also concerned with the need to help students gain more content knowledge and be able to apply their new set of learning skills and knowledge. As a result in their search for different variety of assessments, some universities and colleges are actually reinventing or "freshening up" current assessments to meet today's needs of business and their students. One such assessment is the practicum, which is being offered now in the online learning environment.

\section{PRACTICUMS AND PRACTICAL APPLICATION}

Practicums have been used a final assessment by many educational institutions, both on the undergraduate and graduate level. Spring Arbor University (2011) notes that a practicum should:

provide an opportunity to professionally apply recent and current learning in a work situation. The experience is intended to encourage personal growth through structured goal setting and the opportunity to integrate the several disciplines of the major. A practicum may be the first "real world" experience for a traditional student and can offer him (or her) a means to investigate a potential career field and work with professionals in that field (page1).

As noted above, this "real world" experience may play an important step in the student's current and future career aspirations. Also, it may serve as a stepping stone of learning for both the student and instructor. Even though, many instructors need to follow a certain set of learning objectives, they may not stray (or have enough of time) to discover additional pathways for assisting the student in learning more on their own and apply such knowledge.

Pepperdine University Graziadio School of Business and Management (2011) noted that "practicums provide you with real-world field experience working with professionals from different cultures and backgrounds. You will apply knowledge from the foundation courses and skills developed in the intensives in real time interaction with clients guided by faculty and alumni mentors" (para. 5). The American Public University's graduate Practicum and Integration Project "examines complex organizations from a level of analysis perspective developing competence in organization analysis, management theory and practice, strategy formulation and execution, leadership, human resources management, technology and global issues related to management, and other related areas. .... This program aims to educate professionals for management and business practice in global military, 
government and business environments" (APUS, 2011). Since it has been established here that the application of knowledge is important for assessment of learning, let us now look at possible applications for the practicum experience.

Spring Arbor University (2011) offered a list of possible practicum experiences to include, but not limited to the following.

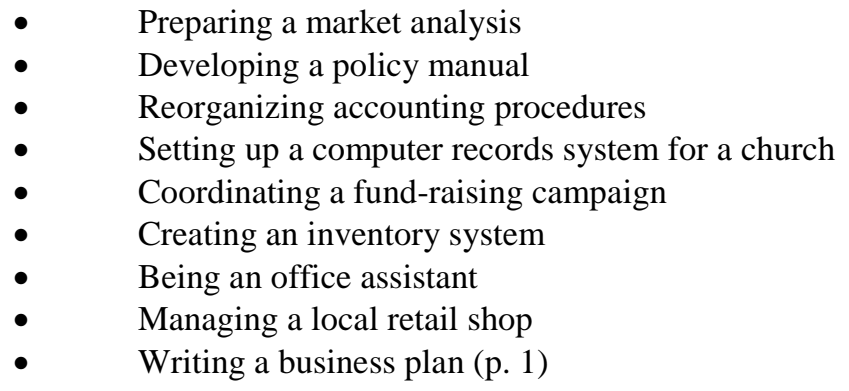

While the above list offers a variety of possible applications, some educational institutions go a step further to narrow down learning events or offer the student some exploration on their own to discover and propose what they might seek in a practicum project. On another note, some practicums are selected by students as another avenue to complete their graduate-level program in lieu of the common comprehensive examination or master's thesis. While not all students may test well with examinations or excel in writing research projects, the use of practicums offer another level of assessment for students.

\section{CREATING ONLINE PRACTICUMS TO VIRTUAL PRACTICUMS}

How do we create an online practicum that will serve the interests of the student both in the real world and online learning environment? The American Public University has been successful in meeting these needs with the creation of an online practicum course that helps students to evaluate their current level of learning and work with them to create a beneficial practicum learning project to assess their level of learning, engage in a real world situation, and to reflect on the overall process. This section will examine how this university has created a workable of assessment for final graduate-level learning, as well as providing a real work application project.

During the first part of the practicum experience, the instructor and student work together to determine a potential set of practicum experiences, as discussed earlier in this paper. Once the student has identified a practicum experience in terms of a potential organization and contact person to work with in this project, the instructor starts the first segment of a coaching session. During the course, there are several coaching sessions. At this juncture of the practicum experience, the instructor sets up a coaching session in which the student and instructor write up a set of learning objectives for the practicum experience. The main focus of this first coaching session is to determine what is the goal of the practicum? Also, both the instructor and student will discuss how the student will proceed with the creation of the learning experience.

Once the first coaching session is completed, the student will proceed to work with the organization's contact person and commence with the practicum work. During this time the student will work on an activity report $\log$ to record his or her hours and document the various tasks completed, along with learning events and happenings that occur during this time. It should be noted that each practicum student is required to have completed 120-150 work hours with their selected (approved) organization. Why is this important? During this time the student will start to reflect on the learning activities and events during the practicum as he or she starts to work on a reflective final project for this course.

The final project for this course will consist of 25-page reflective analysis paper. This paper will describe the student's learning experience, supplemented by current theory and literature applied in the practicum experience. They will examine and explore how this theory and the current literature are applicable to their learning, as well as 
how it might be used in their future career endeavors. Prior to the completion of this final project, there is a second coaching session for the instructor to follow-up with the student and answer any questions or concerns. The final coach session occurs during the final week and when the student is finishing up his or her final reflective analysis paper. This final session offers a final assessment tool in which the instructor and student can openly dialogue about the practicum experience in terms of the strengths and weakness of this experience and how it might be improved upon in future offerings of the course.

\section{CONCLUSION}

While not all assessments will fit all environments, academic standards are still a requirement for all accredited learning environments. However, with the use of technology and various needs of business and industry, educators and administrators must adjust and adapt to these changing needs. As more and more colleges and universities work towards changing their teaching methods and learning activities, practicums are becoming a welcomed and useful form of learning and final assessment for many educational programs. As noted in this paper, there are many different possibilities for practicums in terms of learning experiences and as a form of assessment. The key factor in using practicum is whether or not it fits the needs of the intended program of study for the student, and whether the student can benefit from the use of a practicum versus other conventional forms of final assessment.

\section{AUTHOR INFORMATION}

Dr. Bob Barrett is a professor in the School of Business at the American Public University. Dr. Barrett's current research interests are: Online Learning, Intellectual Capital, Human Resource Development (HRD); Human Resource Management (HRM); Virtual Management Teams; Disability in the Workplace. He speaks both nationally and internationally on these topics, with an emphasis on online learning, disabilities, and intellectual capital/knowledge management. Dr. Barrett currently teaches and writes on the subject of global business in today's changing economic times. E-mail: docjob00@msn.com

\section{REFERENCES}

1. Angelo, T.A, \& Cross, K.P. (1993). Classroom assessment techniques: A handbook for college teachers $\left(2^{\text {nd }}\right.$ ed.). San Francisco: Jossey-Bass.

2. Centre for the Study of Higher Education (2011). Retrieved 1/18/2012 from http://www.cshe.unimelb.edu.au/assessinglearning/03/online.html.

3. Harris, H. (2000). Defining the future or reliving the past? Unions, employers, and the challenge of workplace learning. Columbus, OH: ERIC Clearinghouse on Adult, Career, and Vocational Education, Information Series, No. 380.

4. Huba, M.E., \& Freed, J.E. (1999). Learner-centered assessment on college campuses: Shifting the focus from teaching to learning. Needham Heights, MA: Allyn \& Bacon.

5. $\quad$ NACOL. http://www.nacol.org. Retrieved Oct. 30, 2009.

6. $\quad$ National Center for Education Statistics, 2003).

7. Pepperdine University Graziadio School of Business and Management (2011). Retrieved on 2/21/12 from http://bschool.pepperdine.edu/programs/masters-organization-development/curriculum/

8. Sewell, J.P., Frith, K.H., and Colvin, M.M. (2010). Online assessment strategies: A primer. MERLOT journal of online learning and teaching 6(1).

9. Spring Arbor University (2011). Business Practicum. Retrieved on 2/26/11 from http://www.arbor.edu/uploadedFiles/REDESIGN_2008/Resources_and_FAQs/Offices/Hosmer_Center/Pra cticums/Practicum\%20Guidelines.PDF.

10. Virtual University Design \& Technology (2010). Retrieved 1/18/2012 from http://vudat.msu.edu/teach/student-assessment. 


\section{NOTES}

